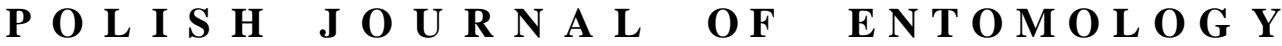

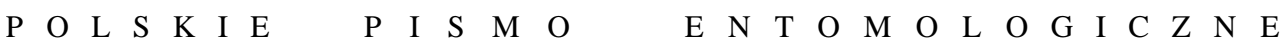

VOL. 86: 49-67

Lublin

31 March 2017

DOI: $10.1515 /$ pjen-2017-0004

\section{Comparative account of energy reserves in four co-occurring mosquito species in Kolkata, India (Diptera: Culicidae)}

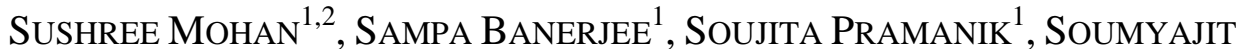 \\ BANERJEE ${ }^{1,3}$, GOUTAM K. SAHA ${ }^{1}$, GAUTAM Aditya ${ }^{1,4^{*}}$ \\ ${ }^{1}$ Department of Zoology, University of Calcutta, 35 Ballygunge Circular Road, Kolkata \\ 700019, India \\ ${ }^{2}$ Department of Zoology, Ravenshaw University, College Square, Cuttack 753003, India \\ ${ }^{3}$ P.G. Department of Zoology, Serampore College, Serampore 712201. India \\ ${ }^{4}$ Department of Zoology, The University of Burdwan, Golapbag, Burdwan 713104, India
}

\begin{abstract}
Energy reserves in mosquitoes are an indicator of fitness, linking larval effort in resource acquisition with adult survival and fecundity. In other words, life history strategies and disease transmission potential can be related to the amount of energy reserves. The energy reserves of four mosquitoes - Aedes aegypti, Aedes albopictus, Armigeres subalbatus and Culex quinquefasciatus (Diptera: Culicidae) - were calculated to justify species-specific differences in their life history strategies. Following repeated sampling of pupae from the respective larval habitats, the glycogen, sugar and lipid contents of individual mosquitoes were assessed and corroborated with pupal weight and adult wing length. Discriminant function analysis was used to acquire an initial reflection of the differences of the parameters among the sex and species of the mosquitoes considered in the study. Using logistic regression and ANOVA, the effects of species and sex as contributors to variations in energy reserves could be established. The results indicated that for all the mosquitoes, sex-specific differences were prominent with reference to the energy reserves. Species-specific differences in energy reserves reflect differences in resource acquisition and assimilation in the tissues, and thus the differences in the life history strategies of these four species.
\end{abstract}

KEY WORDS: energy reserves, mosquito, Aedes, Armigeres, Culex, sexual dimorphism, multivariate analysis.

\footnotetext{
*Corresponding author: gautamaditya2001@yahoo.com; gautamaditya2001@gmail.com
} 


\section{INTRODUCTION}

In mosquitoes, resource acquisition in the larval stages determines the energy reserves in adults. Energy reserves can be regarded as a life history trait owing to their correspondence with the longevity and fecundity of an individual mosquito (MOSTOWY \& FOSTER 2004, BARGIELOWSKI et al. 2012, MAÏGA et al. 2012, KAUFMANN et al. 2013). Body sizes (pupal weight, adult weight, wing length etc.) of mosquitoes are also dependent on larval feeding, so the food resources of larval habitats play a significant role in the mosquito life cycle (ARrivillaGa \& BARRERA 2004, Mogi 2010) and mosquito abundance (BANERJEE et al. 2015). For a particular mosquito species, the larger the size of an individual, the higher the content of protein, glycogen and lipid reserves at emergence, which influences the fecundity and longevity and thereby contributes to the fitness of the mosquito (NASCI 1986, TAKKEN et al. 1998, BRIEGEL 2003). Small, nutritionally deprived mosquito larvae have lower energy reserves than larger ones, as a consequence of which smaller female mosquitoes need to take more blood meals for egg maturation during the adult stage (BRIEGEL 1990, BRIEgel \& TimMERMANN 2001). This has been demonstrated in Aedes aegypti (LiNNAEUS, 1762) (GRIMSTAD \& WALKER 1991, NAKSATHIT et al. 1999), Culex pipiens pallens (LINNAEUS, 1758) (SHIN et al. 2012) and GILES, 1902 (TAKKEN et al. 1998). Energy reserves can thus be considered crucial indicators of larval efforts towards resource acquisition and assimilation in the adult body size, and also determinants of longevity and fecundity.

The disease transmission potential of vector mosquitoes is linked with life history traits like body size and longevity. Empirical studies have shown that vector competence for arboviral pathogens corresponds to the body size and energy reserves in an individual mosquito (TAKAHASHI 1976, BAQAR et al. 1980, PAULSON \& HAWLEY 1991, SUMANOCHITRAPON et al. 1998, MUTURI et al. 2011). Species-specific variations in behavioural and life history strategies have been observed for different vector mosquitoes, which accounts for the varying levels of vector competence (RICHARDS et al. 2012, TABACHNICK 2013, TSURIM et al. 2013). This is evident from the pattern of transmission of different mosquito-borne diseases like malaria, filariasis, Japanese encephalitis and dengue. The oviposition habitat preferences and the developmental pattern of vector mosquitoes may result in differences in life history traits and thus energy reserves. As a consequence of the different strategies for larval development, including resource acquisition, energy reserves in different mosquitoes may vary. Even if mosquitoes develop in the same habitats, their physiological, genetic and morphological features may lead to differences in the developmental pattern and thus resource acquisition and energy reserves. The resource quality of larval habitats can also contribute to the differences in the energy reserves of mosquitoes. For instance, mosquitoes developing in sewage drains vary in larval 
development and consequently in energy reserves, in contrast to those developing in phytotelmata and smaller container habitats (BANERJEE et al. 2015). The hypothesis of species-specific differences in energy reserves is explored in the present study using four different Culicine mosquito species, namely Aedes aegypti, Aedes albopictus (SKUSE, 1894), Armigeres subalbatus (COQUILLETT, 1898) and Culex quinquefasciatus SAY, 1823 (Diptera: Culicidae). In Kolkata, India, the records of the larval habitats of these mosquitoes indicate that Culex quinquefasciatus and Armigeres subalbatus prefer larger larval habitats as breeding sites, while Aedes aegypti and A. albopictus prefer smaller container habitats (ADITYA et al. 2009, ADITYA \& SAHA 2013, BANERJEE et al. 2015). Although field observations provide an impression of the differences in the life history strategies and body sizes of these four mosquitoes, comparative studies of the energy reserves and body size correlates have been made separately, mostly on the basis of inbred laboratory populations (TAKKEN et al. 1998, BRIEGEL 2003, SHIN et al. 2012). Thus, we hypothesize that, if energy reserves are a species-invariant property, the correspondence between body size and energy reserves will remain similar in all the mosquitoes concerned. If it varies with the species, however, differences in life history strategies can be deduced, which in turn may help understand the variations in the transmission of different vector borne diseases.

\section{MATERIAL AND METHODS}

\section{Study sites}

Larval sampling was carried out in six broad areas of Kolkata and surroundings:

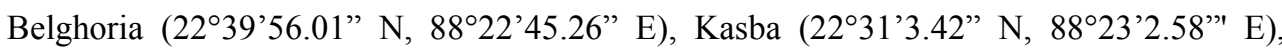

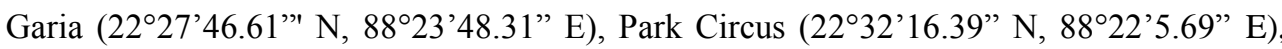
Dankuni $\left(22^{\circ} 40^{\prime} 51.00^{\prime \prime} \mathrm{N}, 88^{\circ} 17^{\prime} 34.55^{\prime \prime}\right.$ E) and Howrah $\left(22^{\circ} 35^{\prime} 44.77^{\prime \prime} \mathrm{N}, 88^{\circ} 15^{\prime} 49.10^{\prime \prime}\right.$ E). The immature stages of four mosquito species - Armigeres subalbatus, Culex quinquefasciatus, Aedes aegypti, and Aedes albopictus - were randomly collected from at least 20 larval habitats of each site using standard sampling methods (BLACKMORE \& LORD 2000, WHO 2003, ADITYA et al. 2009, BANERJEE et al. 2010) from July to September of 2011 and 2012. The collection times and the study period were selected to coincide with the abundance of all four mosquito species. At least 20 prospective larval habitats were surveyed in each month for collections of immature mosquitoes. Sewage drains and storm water pits were regarded as larval habitats for the mosquitoes Armigeres subalbatus and Culex quinquefasciatus (ADITYA et al. 2009, ADITYA \& SAHA 2013), whereas plastic and porcelain containers were considered for the mosquitoes Aedes aegypti and A. albopictus (BANERJEE et al. 2010, 2015). Sampling was continued for different time periods from the 
same geographical locations, such that the samples were random and interspersed in compliance with the norms of replication (HURLBERT 1984).

\section{Larval and pupal sampling and rearing to adult stages}

The pupae and larvae from each positive habitat were collected randomly and placed in sample containers $\left(100 \mathrm{ml}\right.$ sample container Tarsons ${ }^{\circledR}$, India) and brought to the laboratory. There the specimens were placed in plastic trays $(15 \times 11 \times 3 \mathrm{~cm})$ for segregation of pupa and larva, identification and data recording. The pupal weight was measured (wet weight up to the nearest $0.1 \mathrm{mg}$ using an Adam equipment analytical balance, ADA 71/L, UK) in $\mathrm{mg}$ and each pupa was placed in a glass vial (with $5 \mathrm{~mL}$ of deionized water) individually and allowed to emerge as an adult at room temperature $\left(27-30^{\circ} \mathrm{C}\right)$. The larger larvae (late IV instar stages), i.e. those that pupated without any additional food resources within 2 hours of collection, were also considered. The sex and species of the adults were identified on the basis of the relevant keys (CHRISTOPHER 1933, BARRAUD 1934, NAGPAL et al. 2005). Following eclosion, the water in the glass vials was removed and the glass vials along with the adult mosquitoes were stored at $-20^{\circ} \mathrm{C}$ for 2 hours to kill the insects. Then the vials were placed in a hot air oven with a temperature of $40^{\circ} \mathrm{C}$ maintained for 48 hours to dry the samples, following the protocol used elsewhere (TELANG et al. 2006, 2007). This process was adopted for adults emerging within a 2 hour time frame; the remainder were continuously monitored for eclosion to adult stage. In no instance were adult mosquitoes allowed to feed on a sugar solution. One of the wings was then separated from each individual and its length measured to the nearest $0.1 \mathrm{~mm}$ using a dissecting stereo microscope (Olympus ${ }^{\circledR}$ SZX, Olympus Corporation, Tokyo, Japan) fitted with a graduated eyepiece $\left(\right.$ Erma $^{\circledR}$, Japan) (appropriate magnification, scaling and conversion of the eyepiece to $\mathrm{mm}$ was done). The dead mosquitoes were then subjected to biochemical analyses to estimate the energy reserves in each species. Adult eclosion varied in accordance with the numbers of each species collected, and the energy reserves were estimated accordingly.

\section{Estimation of glycogen, sugar and lipid content}

The glycogen, sugar and lipid contents of individual adults of four mosquito species (Armigeres subalbatus, Culex quinquefasciatus, Aedes aegypti and A. albopictus) were estimated following standard methods (VAN HANDEL 1965, 1985a, 1985b). Dead and dried mosquitoes were individually homogenized in $0.2 \mathrm{ml} 2 \%$ sodium sulphate and a few drops of methanol in a $15 \times 155 \mathrm{~mm}$ glass tube. This solution was vortexed (Remi CM 101, India) vigorously, after which a mixture of methanol and chloroform (1:1) was added to it. The tissues were crushed and then stirred. The mixture was centrifuged $\left(\operatorname{HERMLE}^{\circledR} \mathrm{Z}^{\mathrm{Z}} 323 \mathrm{~K}\right.$, 
USA) at 2000 RPM for $20 \mathrm{~min}$. The supernatant was transferred into a $15 \times 155 \mathrm{~mm}$ glass test tube (marked up to $10 \mathrm{ml}$, graduated at $0.1 \mathrm{ml}$ ) for the sugar assay, while the precipitate was left for the glycogen and lipid assays. The test tubes containing sugar were heated to evaporate the solution in it to 0.1-0.2 ml. Anthrone solution was added (up to the $5 \mathrm{ml}$ mark), stirred and heated in a water bath for $17 \mathrm{~min}$. Following this the test tubes were cooled in an ice box and then stirred. The absorbance of the resultant solution was measured at $625 \mathrm{~nm}$ in a spectrophotometer (SHIMADZU ${ }^{\circledR}$ UV-17000, India) and compared with glucose standards.

To the precipitate left earlier, $0.5 \mathrm{ml}$ chloroform and methanol were added and the whole gently shaken. The mixture was centrifuged at 2000 RPM for $10 \mathrm{~min}$ using a HERMLE ${ }^{\circledR}$ Z323K, USA, centrifuge, yielding a supernatant (containing glycogen) and precipitate (lipid). The supernatant containing glycogen was collected in separate test tubes $(15 \times 155 \mathrm{~mm}$, marked up to $10 \mathrm{ml}$, graduated at $0.1 \mathrm{ml})$ and then heated well to evaporate the solution. Next, anthrone solution was added to it (up to the $5 \mathrm{ml}$ mark), stirred and heated in a water-bath for $17 \mathrm{~min}$. It was then allowed to cool in an icebox and stirred. The absorbance of the resultant solution was taken at $625 \mathrm{~nm}$ using spectrophotometer (SHIMADZU ${ }^{\circledR}$ UV-17000, India) and compared with glucose standards.

For estimating the lipid content, the precipitate was dissolved in a mixture of methanol: chloroform (1:1). The test tubes $(15 \times 155 \mathrm{~mm}$, marked up to $10 \mathrm{ml}$, graduated at $0.1 \mathrm{ml})$ were put in a water bath for evaporation and $0.2 \mathrm{ml}$ concentrated sulphuric acid added. Then they were cooled in an icebox and vanilin was added up to the $5 \mathrm{ml}$ mark. The solution was stirred and a reddish colour allowed to develop within $5 \mathrm{~min}$. The absorbance was measured at $525 \mathrm{~nm}$ using a spectrophotometer (SHIMADZU ${ }^{\circledR}$ UV-17000, India) and compared with the lipid standard. All the standard curves for sugar, glycogen and lipids were prepared with $10,20,30,40,50 \mathrm{ml}$ concentrations of glucose and lipid solution $(\mathrm{mg} / \mathrm{ml})$ using the same reagents, and the same treatment was applied to the mosquito tissues. A schematic diagram of the experimental setup is shown in Fig. 1.

\section{Data analysis}

To analyse the sex- and species-specific variations between the energy reserves and the pupal weight and wing length [life history traits i.e. pupal weight, PW (in mg), wing length, WL (in mm), glycogen content, GLY (in mg), sugar content, SUG (in mg) and lipid content, LIP (in mg)], the data were subjected to two-way factorial ANOVA, taking sex and species as explanatory variables. The sex- and species-specific differences in the mosquitoes were further expressed by means of discriminant function analysis (MANLY 1994), in which the relative differences among the eight groups (4 species and 2 sexes) were portrayed using features like pupal weight, wing length, and three levels of energy 
reserves. The results would enable justifying the difference, if any, among the four species considered in the study.

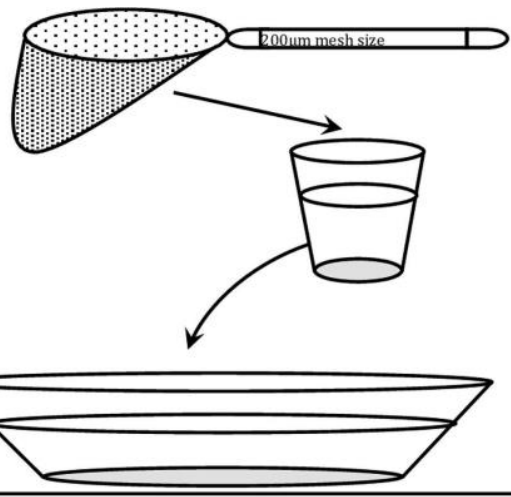

Species wise segregation and placement in individual vials $(25 \times 100 \mathrm{~mm}$ size $)$
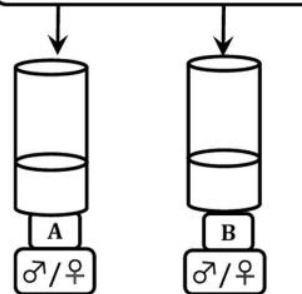

이우
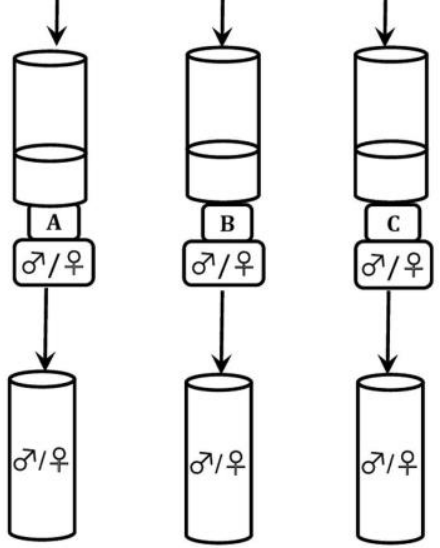

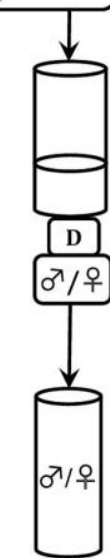
replicate was weighed nearest to

Estimate of energy reserves in terms of glycogen, sucrose and lipids following VAN HANDEL $(1965,1985 a, 1985 b)$
Random stratified sampling of the respective larval habitats of the mosquitoes within the study area.

The collected immature were placed in specimen container (100ml Tarson, India) and brought to the laboratory placed in enamel container for segregation of pupa. For each species separate collections were made in separate dates and larval habitats. Tap and distilled water in equal ratio was used in the glass trough during separation and further treatment of the pupa.

Individual pupa from each $0.1 \mathrm{mg}$ and placed in a vial with $5 \mathrm{~mL}$ of deionized water for eclosion with appropriate marking against the vials for

future records

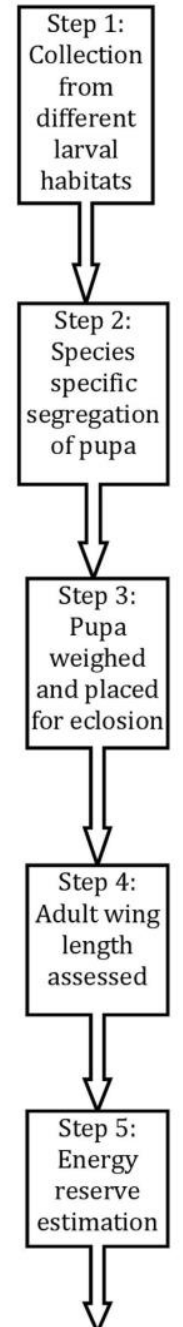

Eclosion to adult mosquito in individual vials. Death and dried, wing length was measured using ocular micrometer

Hypothesis tested: Species specific differences in energy reserves and life history traits and establishment of energy reserves as markers of individual fitness.

Fig. 1. Outline of experimental design to estimate the relation between life history traits and energy reserves. A - Armigeres subalbatus, B - Culex quiquefasciatus, C - Aedes aegypti, $\mathrm{D}-\mathrm{A}$. albopictus. 
A logistic regression complying with the binomial generalized linear model with logit link was employed to comment on the sex- and species-specific variations in the life history traits of the four mosquito species using sex and species as explanatory variables. In the logistic regression, a particular life history trait (response variable) is assumed to follow a binomial ( $\mathrm{n}, \mathrm{p}$ ) distribution with $\mathrm{n}$ replicates (sampling efforts) for each level of explanatory variables (the levels of the explanatory variables: Sex-2, Species-4). The linear combination of the explanatory variables is represented through the probability parameter p. A weighted binary function with logit link was employed and the parameters were estimated by maximum likelihood using XLSTAT software (ADDIN SOFT 2010). The equation is represented as a life history trait $(y)=1 /\left(1+\exp \left(-\left(a+b_{1} x_{1}-b_{2} x_{2}\right)\right)\right)$, where $x_{1}$ is species, $\mathrm{x}_{2}$ is sex. A Chi square value (Wald's Chi-square) was used to deduce the significant contribution of the explanatory variables. All statistical analyses were done following ZAR (1999).

The difference between the male and female adult mosquitoes with respect to glycogen, sugar and lipid contents were highlighted by the degree of sexual dimorphism (SHARMILA BHARATHI et al. 2004) using the following formula:

$$
\text { Degree of sexual dimorphism }(\mathrm{DD})=\left(\mathrm{ER}_{\mathrm{F}}-\mathrm{ER}_{\mathrm{M}}\right) /\left[\left(\mathrm{ER}_{\mathrm{F}}+\mathrm{ER}_{\mathrm{M}}\right) / 2\right]
$$

where $\mathrm{ER}_{\mathrm{F}}=$ energy reserve of the $i$ th female and $\mathrm{ER}_{\mathrm{M}}=$ energy reserve of the $i$ th male.

Prior to this, the data on the glycogen, sugar and lipid contents of individuals were weighted and scaled separately by taking the corresponding pupal weight as the denominator. The values were then arranged in ascending order for the two sexes, in accordance with the respective pupal weight, and DD was calculated for glycogen, sugar and lipid separately, using the above formula. The difference between males and females was judged to be significant by the deviation from 0 (no difference) (ZAR 1999) using the one-tailed t-test for each of the four mosquito species.

\section{RESULTS}

The pupal weight and wing length of the mosquitoes varied with the species and sex, with Armigeres subalbatus and Culex quinquefascitus exhibiting higher values than the Aedes mosquitoes. Irrespective of the mosquito species, the mean values of the pupal weight and the wing length of the males were smaller than in the females (Table 1). The energy reserves of the four mosquito species, when expressed as a function of unit pupal weight, were found to vary according to species, but no fixed pattern for the sex-specific variation was found (Fig. 2). The results of the two-way factorial ANOVA indicate that 
Table 1. The values (Range, Mean $\pm \mathrm{SE}$ ) of the pupal weight (PW), adult wing length (WL) and energy reserves (Sugar, SUG, Glycogen, GLY, and Lipid, LIP,) of the four mosquito species collected from larval habitats in Kolkata, India. Sp. - Species: Armigeres subalbatus (Asu), Culex quinquefasciatus (Cqu), Aedes aegypti (Aae) and A. albopictus (Aal).

\begin{tabular}{|c|c|c|c|c|c|c|}
\hline Sp. & Sex & PW [mg] & WL [mm] & GLY [mg] & SUG [mg] & LIP [mg] \\
\hline \multirow{2}{*}{ Asu } & $\begin{array}{l}\mathrm{q} \\
\mathrm{N}=77\end{array}$ & $\begin{array}{l}4.50-6.20 \\
5.62 \pm 0.06\end{array}$ & $\begin{array}{l}4.690-5.020 \\
4.880 \pm 0.009\end{array}$ & $\begin{array}{l}1.500-1.600 \\
1.560 \pm 0.003\end{array}$ & $\begin{array}{l}0.216-0.289 \\
0.239 \pm 0.002\end{array}$ & $\begin{array}{l}0.214-0.333 \\
0.293 \pm 0.004\end{array}$ \\
\hline & $\begin{array}{l}\hat{O} \\
\mathrm{~N}=77\end{array}$ & $\begin{array}{l}4.50-6.20 \\
5.62 \pm 0.06\end{array}$ & $\begin{array}{l}4.670-5.000 \\
4.860 \pm 0.009\end{array}$ & $\begin{array}{c}1.500-1.600 \\
1.55 \pm 0.002\end{array}$ & $\begin{array}{l}0.213-0.280 \\
0.234 \pm 0.002\end{array}$ & $\begin{array}{l}0.199-0.321 \\
0.280 \pm 0.004\end{array}$ \\
\hline \multirow{2}{*}{ Cqu } & $\begin{array}{l}\text { P } \\
\mathrm{N}=102\end{array}$ & $\begin{array}{l}2.00-2.30 \\
2.12 \pm 0.01\end{array}$ & $\begin{array}{l}4.590-4.920 \\
4.830 \pm 0.010\end{array}$ & $\begin{array}{l}0.230-0.260 \\
0.250 \pm .0010\end{array}$ & $\begin{array}{l}1.206-1.370 \\
1.360 \pm 0.003\end{array}$ & $\begin{array}{l}0.010-0.050 \\
0.030 \pm 0.001\end{array}$ \\
\hline & $\begin{array}{l} \\
\mathrm{N}=102\end{array}$ & $\begin{array}{l}1.70-2.10 \\
1.85 \pm 0.01\end{array}$ & $\begin{array}{l}4.590-4.920 \\
4.790 \pm 0.010\end{array}$ & $\begin{array}{l}0.230-0.260 \\
0.240 \pm 0.001\end{array}$ & $\begin{array}{l}1.120-1.370 \\
1.240 \pm 0.010\end{array}$ & $\begin{array}{l}0.010-0.040 \\
0.028 \pm 0.001\end{array}$ \\
\hline \multirow{2}{*}{ Aae } & $\begin{array}{l}\text { P } \\
\mathrm{N}=100\end{array}$ & $\begin{array}{l}2.30-4.70 \\
3.82 \pm 0.06\end{array}$ & $\begin{array}{l}2.290-6.710 \\
3.080 \pm 0.060\end{array}$ & $\begin{array}{l}0.128-0.618 \\
0.223 \pm 0.011\end{array}$ & $\begin{array}{l}0.042-0.816 \\
0.155 \pm 0.010\end{array}$ & $\begin{array}{l}0.021-0.062 \\
0.044 \pm 0.001\end{array}$ \\
\hline & $\begin{array}{l}\text { गे } \\
\mathrm{N}=100\end{array}$ & $\begin{array}{l}0.50-3.42 \\
1.98 \pm 0.07\end{array}$ & $\begin{array}{l}1.800-3.390 \\
2.450 \pm 0.030\end{array}$ & $\begin{array}{l}0.027-0.611 \\
0.221 \pm 0.012\end{array}$ & $\begin{array}{l}0.038-0.507 \\
0.149 \pm 0.007\end{array}$ & $\begin{array}{l}0.015-0.054 \\
0.038 \pm 0.001\end{array}$ \\
\hline \multirow{2}{*}{ Aal } & $\begin{array}{l}\text { P } \\
\mathrm{N}=100\end{array}$ & $\begin{array}{l}1.80-4.30 \\
2.60 \pm 0.06\end{array}$ & $\begin{array}{l}2.150-3.600 \\
2.760 \pm 0.003\end{array}$ & $\begin{array}{l}0.040-0.568 \\
0.160 \pm 0.012\end{array}$ & $\begin{array}{l}0.036-0.437 \\
0.134 \pm 0.005\end{array}$ & $\begin{array}{l}0.019-0.058 \\
0.042 \pm 0.001\end{array}$ \\
\hline & $\begin{array}{l}\hat{\partial} \\
\mathrm{N}=100\end{array}$ & $\begin{array}{l}0.50-3.00 \\
1.86 \pm 0.06\end{array}$ & $\begin{array}{l}1.120-2.440 \\
2.070 \pm 0.010\end{array}$ & $\begin{array}{l}0.053-0.571 \\
0.158 \pm 0.009\end{array}$ & $\begin{array}{l}0.018-0.494 \\
0.133 \pm 0.007\end{array}$ & $\begin{array}{l}0.008-0.053 \\
0.031 \pm 0.001\end{array}$ \\
\hline
\end{tabular}

pupal weight shows both species- and sex-specific variations but that wing length varied significantly only with the species. Whereas energy reserves, particularly of sugar, varied significantly for the four different species, both glycogen and lipid reserves showed both species- and sex-specific variation (Table 2). The results of the GLM resulted in significant differences in the pupal weight as explained by the sex and species of the mosquitoes, whereas the wing length displayed species-specific variation. The significant contribution of sex and species were observed across the values of Wald's Chi-square values (Table 3). The results of the discriminant function analysis highlighted the differences among the mosquitoes and the two sexes with considerable resolution (Fig. 3). The first two extracted factors were able to explain $93 \%$ of the variation in the data on pupal weight, wing length and energy reserves. Significant values of the Mahalnobis distance matrix among the species and sex of the mosquitoes were manifested owing to the differences in the life history traits and energy reserves. Irrespective of the sexes, the differences between Culex quinquefasciatus and Armigeres subalbatus were greater than those between Aedes aegypti and A. albopictus. The results of the discriminant function analysis as well as factorial ANOVA indicate that the four mosquito species differed significantly in terms of pupal weight, wing length and energy reserves. Comparison of the degree of sexual dimorphism indicated that the female mosquitoes were larger than the males (Fig. 4). As a consequence, 
the extent of differences between the two sexes was not pronounced in case of the energy reserves weighed according to pupal weight. Since the female mosquitoes were heavier in size, the contribution per unit biomass of pupa reduced the value of the energy reserves to a greater extent than in their male counterparts.

Table 2. The results of two-way factorial ANOVA using the sex and species of the mosquitoes as the source of variations for the response variables pupal weight (PW), wing length (WL), glycogen (GLY), sugar (SUG) and lipid (LIP) reserves. The values in bold represent significance at $\mathrm{P}<0.05$ level.

\begin{tabular}{|c|c|c|c|c|}
\hline Source & DF & Sum of squares & Mean squares & $\mathbf{F}$ \\
\hline \multicolumn{5}{|c|}{ PW $[\mathrm{mm}]$} \\
\hline Species & 3 & 1390.135 & 463.378 & 1802.472 \\
\hline Sex & 1 & 109.108 & 109.108 & 424.415 \\
\hline Species*Sex & 3 & 92.854 & 30.951 & 120.396 \\
\hline Error & 750 & 192.810 & 0.257 & \\
\hline Total & 757 & 1784.907 & & \\
\hline \multicolumn{5}{|c|}{ WL [mm] } \\
\hline Species & 3 & 969.532 & 323.177 & 4104.991 \\
\hline Sex & 1 & 0.000316 & 0.000316 & 0.004 \\
\hline Species*Sex & 3 & 43.824 & 14.608 & 185.549 \\
\hline Error & 750 & 59.046 & 0.079 & \\
\hline Total & 757 & 1072.401 & & \\
\hline \multicolumn{5}{|c|}{ SUG [mg] } \\
\hline Species & 3 & 1.870 & 0.623 & 198.147 \\
\hline Sex & 1 & 0.002 & 0.002 & 0.730 \\
\hline Species*Sex & 3 & 0.011 & 0.004 & 1.176 \\
\hline Error & 750 & 2.360 & 0.003 & \\
\hline Total & 757 & 4.243 & & \\
\hline \multicolumn{5}{|c|}{ GLY [mg] } \\
\hline Species & 3 & 286.664 & 95.555 & 13147.700 \\
\hline Sex & 1 & 0.202 & 0.202 & 27.795 \\
\hline Species*Sex & 3 & 0.490 & 0.163 & 22.494 \\
\hline Error & 750 & 5.451 & 0.007 & \\
\hline Total & 757 & 292.807 & & \\
\hline \multicolumn{5}{|c|}{ LIP [mg] } \\
\hline Species & 3 & 7.732 & 2.577 & 7671.371 \\
\hline Sex & 1 & 0.011 & 0.011 & $\mathbf{3 1 . 7 3 3}$ \\
\hline Species*Sex & 3 & 0.004 & 0.001 & 3.961 \\
\hline Error & 750 & 0.252 & 0.000336 & \\
\hline Total & 757 & 7.999 & & \\
\hline
\end{tabular}


Table 3. The results of the logistic regression (binomial generalized linear model) with logit link to deduce the variations in the life history traits and energy reserves of the four mosquito species, using sex and species as explanatory variables. Species-specific variations were consistent for all the response variables considered.

$$
\begin{gathered}
\text { PW }=1 /(1+\exp (-(-5.58-0.28 * \text { Species-0.25*Sex }))) \\
\text { WL }=1 /(1+\exp (-(-5.98-0.27 * \text { Species-0.0003*Sex }))) \\
\text { SUG }=1 /(1+\exp (-(-6.05-0.22 * \text { Species-0.018*Sex }))) \\
\text { GLY }=1 /(1+\exp (-(-4.91-0.77 * \text { Species-0.043*Sex }))) \\
\text { LIP }=1 /(1+\exp (-(-4.63-0.88 * \text { Species-0.086*Sex })))
\end{gathered}
$$

\begin{tabular}{|c|c|c|c|c|}
\hline Variable & Factor & Intercept & Species & Sex \\
\hline \multirow{4}{*}{ PW } & Value & -5.584 & -0.278 & -0.252 \\
\cline { 2 - 5 } & SE & 0.078 & 0.020 & 0.042 \\
\cline { 2 - 5 } & Wald $\chi^{2}$ & 5148.091 & 202.152 & 35.863 \\
\cline { 2 - 5 } & $\operatorname{Pr}>\chi^{2}$ & $<0.0001$ & $<0.0001$ & $<0.0001$ \\
\hline \multirow{4}{*}{ WL } & Value & -5.980 & -0.267 & 0.0003 \\
\cline { 2 - 5 } & SE & 0.073 & 0.018 & 0.038 \\
\cline { 2 - 5 } & Wald $\chi^{2}$ & 6797.450 & 224.307 & 0.0001 \\
\cline { 2 - 5 } & $\operatorname{Pr}>\chi^{2}$ & $<0.0001$ & $<0.0001$ & 0.992 \\
\cline { 2 - 5 } & Value & -6.049 & -0.219 & -0.018 \\
\cline { 2 - 5 } & SE & 0.318 & 0.077 & 0.166 \\
\cline { 2 - 5 } & Wald $\chi^{2}$ & 361.809 & 8.039 & 0.012 \\
\hline \multirow{4}{*}{ GLY } & Pr $>\chi^{2}$ & $<0.0001$ & 0.005 & 0.912 \\
\cline { 2 - 5 } & Value & -4.906 & -0.768 & -0.043 \\
\cline { 2 - 5 } & SE & 0.153 & 0.045 & 0.083 \\
\cline { 2 - 5 } & Wald $\chi^{2}$ & 1024.474 & 286.648 & 0.264 \\
\hline \multirow{5}{*}{ LIP } & Pr $>\chi^{2}$ & $<0.0001$ & $<0.0001$ & 0.607 \\
\cline { 2 - 5 } & Value & -4.633 & -0.881 & -0.086 \\
\cline { 2 - 5 } & SE & 0.450 & 0.141 & 0.245 \\
\cline { 2 - 5 } & Wald $\chi^{2}$ & 106.100 & 39.178 & 0.123 \\
\cline { 2 - 5 } & Pr $>\chi^{2}$ & $<0.0001$ & $<0.0001$ & 0.726 \\
\hline
\end{tabular}

\section{DISCUSSION}

In mosquitoes and other insects, life history traits like wing length and pupal weight can be considered indicators of reproductive success and fitness (AGNEW et al. 2000, 2002, BRIEGEL 2003). In different species of mosquitoes the correspondence among pupal weight, wing length, longevity and fecundity justifies the use of one or many life history traits as markers of fitness at the individual or population level (BLACKMORE \& LORD 2000, PADMANABHA et al. 2011a, 2011b, MUTURI et al. 2012). The amount of energy reserves in 

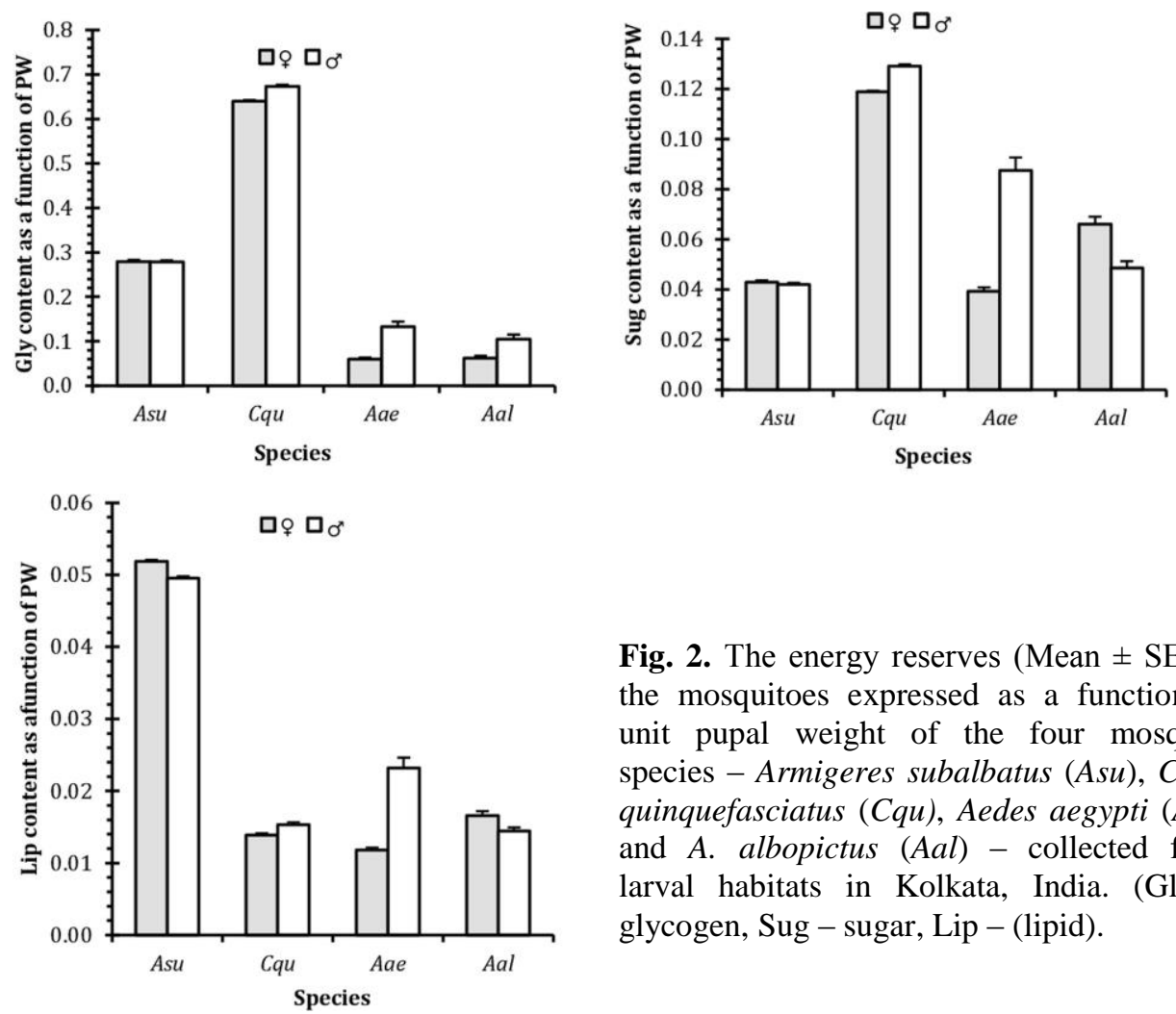

Fig. 2. The energy reserves (Mean $\pm \mathrm{SE}$ ) of the mosquitoes expressed as a function of unit pupal weight of the four mosquito species - Armigeres subalbatus (Asu), Culex quinquefasciatus (Cqu), Aedes aegypti (Aae) and A. albopictus (Aal) - collected from larval habitats in Kolkata, India. (Gly glycogen, Sug - sugar, Lip - (lipid).

an individual mosquito can also be included as an indicator of fitness, owing to the correspondence with multiple life history traits (MOSTOWY \& FosTeR 2004, BARGIELOWSKI et al. 2012, MAÏGA et al. 2012, KAUfMANN et al. 2013). The link between life history traits and energy reserves form the basis for using them as an indicator of reproductive success and fitness at individual and population levels. Pupal weight and wing length have been incorporated in many entomological surveillance studies to predict population size and abundance and thus the chances of mosquito borne diseases (BLACKMORE \& LORD 2000, STRICKMAN \& KITTAYAPONG 2003, BANERJEE et al. 2013a, 2013b). A positive correlation between pupal weight and energy reserves has been demonstrated in a number of mosquito species, including Aedes aegypti and A. albopictus (CHAMBERS \& KlOWDEN 1990, SHIN et al. 2012). As a result of positive correlations, pupal weight is used as a suitable predictor of adult body size (adult weight and wing length) and energy reserves in mosquitoes. The observations of the present study justify this proposition, since the energy reserves showed correspondence with pupal weight and wing 
(a)

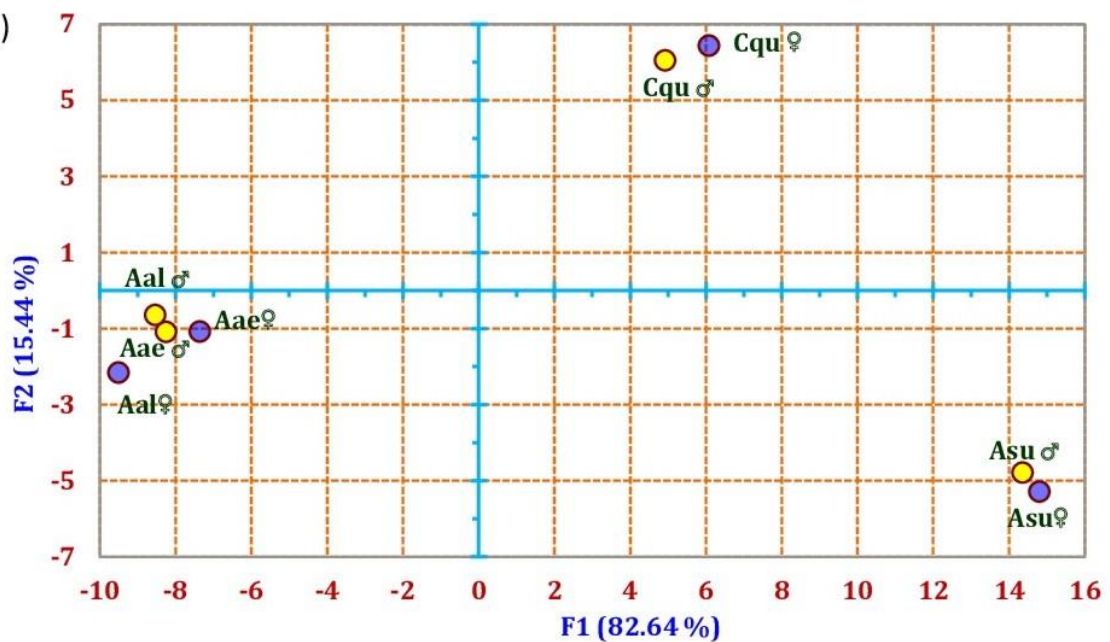

(b)

\begin{tabular}{lrrrrr}
\hline & F1 & F2 & F3 & \multicolumn{1}{c}{ F4 } & \multicolumn{1}{c}{ F5 } \\
\hline Eigenvalue & 90.063 & 16.823 & 1.686 & 0.397 & 0.009 \\
Discrimination (\%) & 82.643 & 15.437 & 1.547 & 0.364 & 0.008 \\
Cumulative \% & 82.643 & 98.080 & 99.628 & 99.992 & 100.000 \\
Canonical correlations: & 0.994 & 0.972 & 0.792 & 0.533 & 0.094 \\
\hline Standardized canonical discriminant functions coefficients & & \\
\hline PW & -0.087 & -0.128 & 1.066 & -0.426 & -0.021 \\
WL & 0.463 & 0.334 & 0.335 & 0.755 & 0.012 \\
SUG & 0.103 & 0.064 & -0.169 & 0.057 & 1.004 \\
GLY & 0.787 & 0.319 & -0.116 & -0.501 & -0.149 \\
LIP & 0.517 & -0.811 & -0.529 & 0.323 & 0.054 \\
\hline
\end{tabular}

(c)

\begin{tabular}{|c|c|c|c|c|c|c|c|}
\hline & Aae 오 & Aae $\hat{\jmath}$ & $\mathrm{Aal}$ 오 & Aal $\hat{0}^{\top}$ & $A s u$ 옹 & Asu $\hat{O}^{\pi}$ & Cqu ㅇ \\
\hline Aae ${ }^{\hat{\sigma}}$ & 20.832 & & & & & & \\
\hline $\mathrm{Aal}+$ & 20.430 & 4.797 & & & & & \\
\hline $\mathrm{Aal}$ है & 18.501 & 1.947 & 8.594 & & & & \\
\hline Asu 우 & 520.22 & 551.34 & 602.69 & 568.46 & & & \\
\hline Asu $\widehat{O}$ & 493.82 & 527.26 & 577.27 & 543.87 & 0.685 & & \\
\hline $\mathrm{Cqu}$ 우 & 245.86 & 264.81 & 317.57 & 267.70 & 214.37 & 194.45 & \\
\hline Cqu ${ }^{\circ}$ & 212.46 & 226.04 & 277.47 & 227.19 & 226.48 & 206.56 & 2.241 \\
\hline
\end{tabular}

Fig. 3. The results of the discriminant analysis using pupal weight (PW), wing length (WL), energy reserves (GLY=glycogen, $\mathrm{SUG}=$ sugar and $\mathrm{LIP}=$ lipid) as explanatory variables against the four mosquito species as response variables (Aal = Aedes albopictus, Aae = Aedes aegypti, Asu = Armigeres subalbatus and $C q u=C$ Culex quinquefasciatus; $\hat{\sigma}=$ male and $q=$ female). The results are represented as: (a) a biplot with the ordination of the mosquitoes in two axes, (b) eigenvalues and canonical correlations and the standardized canonical discriminant function coefficients and (c) the Mahalnobis distance matrix for the response variables (values in bold are significant at $\mathrm{P}<0.001$ ). Wilk's $\lambda$ yielded a significant F-value justifying the application of discriminant function analysis (Wilk's $\lambda=$ $\left.0.0002 ; \mathrm{F}_{35,3141}=624.010 ; \mathrm{P}<0.0001\right)$. 

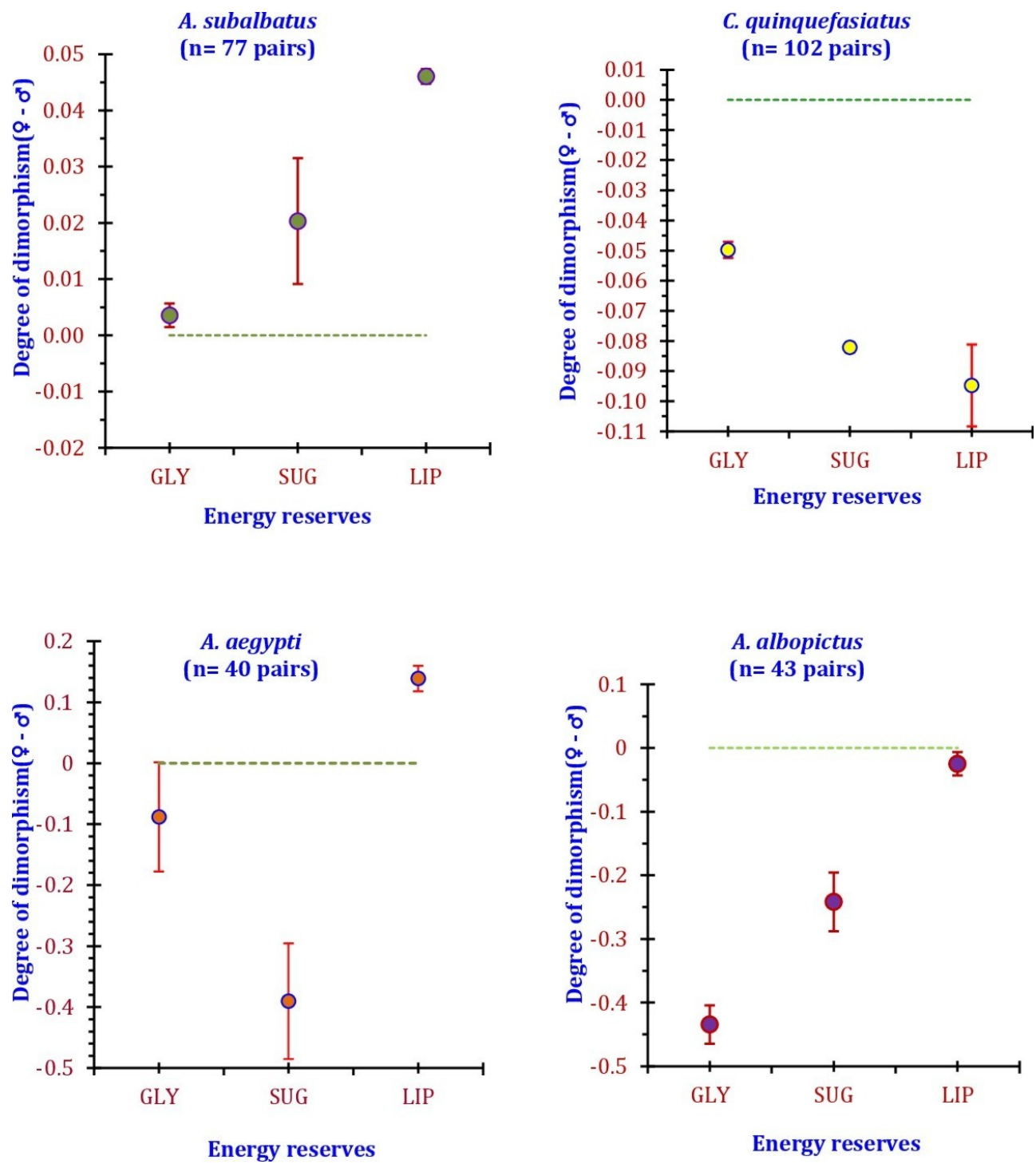

Fig. 4. The degree of sexual dimorphism with reference to energy reserves in four mosquito species. The values of the energy reserves are scaled in accordance with the pupal weight of the individuals to make them comparable among the four species. The values (except Aedes albopictus glycogen; $\mathrm{t}_{43,(1)}=2.5 ; \mathrm{P}<0.05$ ) did not differ significantly from 0 (dashed line, representing no difference) based on the one-tailed t-test. 
length of Aedes aegypti, A. albopictus, Armigeres subalbatus and Culex quinquefasciatus. Although earlier studies demonstrated the relation between life history traits and energy reserves in Aedes mosquitoes (VAIDYANATHAN et al. 2008), the present study is a pioneer effort to report the same for the mosquitoes Armigeres subalbatus and Culex quinquefasciatus from the geographical region concerned. In most instances, laboratory reared mosquitoes are used for estimating energy reserves, except for the few where field collected individuals are used (STRICKMAN \& KITTAYAPONG 2003, BANERJEE et al. 2015). Estimation of the pupal weight and energy reserves of field collected mosquitoes collate the amount of resources exploited and assimilated by the larval stages. Variations in energy reserves within and between the mosquitoes thus reflects the acquisition of resources and their subsequent assimilation by the larval stages developing in the respective larval habitats under natural conditions, which was observed in the four mosquito species considered in the present study.

Although mosquitoes may vary in terms of larval developmental time and adult features (LEHMANN et al. 2006, DA-SiLVA ARAÚJO et al. 2012), the predictability of pupal weight for the adult body size and energy reserves remains an invariant property. In the present study, the correspondence between pupal weight, wing length and energy reserves substantiates this proposition. However, species-specific variations were observed, with the pupal weight of Culex quinquefasciatus and Armigeres subalbatus being considerably higher than that of Aedes aegypti and A. albopictus. The sex specific differences were observed to be an invariant property of the four mosquito species. As a result, the energy reserves per unit pupal weight varied in both a sex- specific and a species-specific manner, represented by the degree of sexual dimorphism. Even though constancy in energy reserves among the species may not be the same owing to differences in feeding activity, resource acquisition and assimilation, the sex-specific differences may remain invariant. The survival and reproductive strategies of the female mosquito differ from the male in many senses, at least one of which is related to egg production and maturation (BRIEGEL 2003). Energy expenditure for egg maturation is somewhat higher than for sperm production, if the unit biomasses of mosquito sperms and eggs are considered. Therefore, females would require a higher amount of energy to mature as an adult than males. However, constancy of biomass and energy reserves in all the species is not observed, owing to the differences in the life history strategies as well as the evolutionary consequences that lead different species of mosquitoes to mature at different sizes and biomass. Thus the observed differences among the species of mosquitoes can be attributed to the way natural selection has shaped them. In general, the energy reserves of the female mosquitoes are higher than their male counterparts as obtained from the laboratory reared populations (FOSTER 1995, 2008, BANERJEE et al. 2015, YU et al. 2016). This may differ when scaled with the pupal weight. The mean biomass of a female pupa was higher than the male one, so unit energy 
reserves per pupal biomass may be skewed towards the male. This was observed in the present instance for all the four mosquitoes collected from nature. However, variations in the pupal weight was not considerably high as known for the four mosquito species considered (ADITYA \& SAHA 2013, BANERJEE et al. 2013a, 2013b, 2015), thereby leaving a chance of error to generalize the observations of the present study. Energy reserves show a considerable positive correlation with the pupal weight, but may be controlled with the developmental requirements of somatic and reproductive tissues (JULIANO et al. 2004, MurRell \& Juliano 2008, ARrivillaga \& BARRERA 2004, BARRERA et al. 2008). Thus the variations in energy reserves observed in the four co-occurring mosquitoes are a reflection of the differences in their life history strategies and adaptations to environmental conditions. It needs to be tested further whether the variations in energy reserves in these mosquitoes correspond to a preference for oviposition habitat selection and the resources available therein.

\section{ACKNOWLEDGEMENTS}

The critical comments of the reviewers, enabling the quality of the present version of the manuscript to be enhanced, are gratefully acknowledged. The authors are grateful to the Head, Department of Zoology, University of Calcutta, for the facilities provided, including DST-FIST. SB acknowledges the financial assistance received through the DST-INSPIRE fellowship [Sanction number: DST/INSPIRE Fellowship/2013/645, dated 17.12.13] for carrying out part of the research work included in the article.

\section{REFERENCES}

ADDIN SOFT SARL 2010. XLSTAT software, Version 10.0. Paris, France.

Aditya G., PramaniK M.K., SAHA G.K. 2009. Immatures of Aedes aegypti in Darjeeling Himalayas expanding geographical limits in India. Indian Journal of Medical Research 129(4): 455-457.

ADITYA G., SAHA G.K. 2013. Estimate of survivorship of immature stages of the mosquito Armigeres subalbatus (COQUILLETT, 1898). Invertebrate Reproduction and Development 57(3): 200-207.

Agnew P., Haussy C., MichalaKis Y. 2000. Effects of density and larval competition on selected life history traits of Culex pipiens quinquefasciatus (Diptera: Culicidae). Journal of Medical Entomology 37(5): 732-735.

Agnew P., Hide M., Sidobre C., Michalakis Y. 2002. A minimalist approach to the effects of density dependent competition on insect life history traits. Ecological Entomology 27(4): 396-402. 
Arrivillaga J., Barrera R. 2004. Food as a limiting factor for Aedes aegypti in water-storage containers. Journal of Vector Ecology 29(1): 11-20.

BanerJee S., Aditya G., Saha G.K. 2013a. Pupal productivity of dengue vectors in Kolkata, India: implications for vector management. Indian Journal of Medical Research 137(3): 549-559.

BANERJeE S., Aditya G., SAHA G.K. 2013b. Household disposables as breeding habitats of dengue vectors: linking wastes and public health. Waste Management 33(1): 233-239.

BANERJee S., Aditya G., SAHA G.K. 2015. Household wastes as larval habitats of Dengue vectors: comparison between urban and rural areas of Kolkata, India. PLoS ONE 10(10): e0138082.

BanerJee S., Aditya G., Saha N., Saha G.K. 2010. An assessment of macroinvertebrate assemblages in mosquito larval habitats - space and diversity relationship. Environmental Monitoring and Assessment 168(1): 597-611.

Baqar S., Hayes C.G., AhMed J. 1980. The effect of larval rearing conditions and adult age on the susceptibility of Culex tritaeniorhynchus to infection with West Nile virus. Mosquito News 40: $165-171$.

Bargielowski I., Kaufmann C., Alphey L., Reiter P., Koella J. 2012. Flight performance and teneral energy reserves of two genetically-modified and one wild-type strain of the yellow fever mosquito Aedes aegypti. Vector-Borne and Zoonotic Diseases 12(1): 1053-1058.

BARRAUd P.J. 1934. Fauna of British India, including Ceylon and Burma. Diptera (Family Culicidae: Tribes Megarginini and Culicini), vol. V. Taylor and Francis, London, UK.

Barrera R., Amador M., Diaz A., Smith J., Munoz-Jordan J.L., Rosario Y. 2008. Unusual productivity of Aedes aegypti in septic tanks and its implications for dengue control. Medical and Veterinary Entomology 22(1): 62-69.

Bédhomme S., Agnew P., Sidobre C., Michalakis Y. 2005. Pollution by conspecifics as a component of intraspecific competition among Aedes aegypti larvae. Ecological Entomology 30(1): $1-7$.

BLACKMORE M.S., LORD C.C. 2000. The relationship between size and fecundity in Aedes albopictus. Journal of Vector Ecology 25(2): 212-217.

BRIEGEL H. 1990. Fecundity, metabolism, and body size in Anopheles (Diptera: Culicidae), vectors of malaria. Journal of Medical Entomology 27(5): 839-850.

BRIEGEL H. 2003. Physiological bases of mosquito ecology. Journal of Vector Ecology 28(1): 1-11.

Briegel H., Timmermann S.E. 2001. Aedes albopictus (Diptera: Culicidae): Physiological Aspects of Development and Reproduction. Journal of Medical Entomology 38(4): 566-571.

Chambers G.M., Klowden M.J. 1990. Correlation of nutritional reserves with a critical weight for pupation in larval Aedes aegypti mosquitoes. Journal of the American Mosquito Control Association 6(3): 394-399.

Christophers S.R. 1933. The fauna of British India including Ceylon and Burma. Diptera, Family Culicidae, Tribe Anophelini. Vol. IV. Taylor and Francis, London, UK.

Da-Silva Araújo M., Gil L.H.S, De-Almeida e-Silva A. 2012. Larval food quantity affects development time, survival and adult biological traits that influence the vectorial capacity of Anopheles darlingi under laboratory conditions. Malaria Journal 11(261): 1-9. 
FosteR W.A. 1995. Mosquito sugar feeding and reproductive energetic. Annual Review of Entomology 40: 437-443.

FOSTER W.A. 2008. Phytochemicals as population sampling lures. Journal of the American Mosquito Control Association 24(1): 138-146.

GRIMSTAD P.R., WALKER E.D. 1991. Aedes triseriatus (Diptera: Culicidae) and La Crosse Virus. IV. Nutritional deprivation of larvae affects the adult barriers to infection and transmission. Journal of Medical Entomology 28(3): 378-386.

HuRLBERT S.H. 1984. Pseudoreplication and the design of ecological field experiments. Ecological Monographs 54(2): 187-192.

Juliano S.A., Lounibos L.P., O’MeARA G.F. 2004. A field test for competitive effects of Aedes albopictus on Ae. aegypti in South Florida: differences between sites of coexistence and exclusion? Oecologia 139(4): 583-593.

Kaufmann C., Collins L.F., Brown M.R. 2013. Influence of age and nutritional status on flight performance of the Asian tiger mosquito Aedes albopictus (Diptera: Culicidae). Insects 4(3): 404-412.

Lehmann T., Dalton R., Kim E.H., Dahl E., Diabate A., Dabire R., Dujardin J.P. 2006. Genetic contribution to variation in larval development time, adult size, and longevity of starved adults of Anopheles gambiae. Infection, Genetics and Evolution 6(5): 410-416.

Maïga H., Dabiré R.K., Lehmann T., Tripet F., Diabaté A. 2012. Variation in energy reserves and role of body size in the mating system of Anopheles gambiae. Journal of Vector Ecology 37(2): 289-297.

MANLY B.F.J. 1994. Multivariate statistical methods: a primer, Second Edition. Chapman and Hall, London, UK.

Mogi M. 2010. Unusual life history traits of Aedes (Stegomyia) mosquitoes (Diptera: Culicidae) inhabiting Nepenthes pitchers. Annals of Entomological Society of America 103(4): 618-624.

Mostowy W.M., Foster W.A. 2004. Antagonistic effects of energy status on meal size and eggbatch size of Aedes aegypti (Diptera: Culicidae). Journal of Vector Ecology 29(1): 84-93.

MurRell E.G., Juliano S.A. 2008. Detritus type alters the Outcome of interspecific competition between Aedes aegypti and Aedes albopictus (Diptera: Culicidae). Journal of Medical Entomology 45(3): 375-383.

Muturi E.J., Blackshear Jr. M., Montgomery A. 2012. Temperature and density-dependent effects of larval environment on Aedes aegypti competence for an alphavirus. Journal of Vector Ecology 37(1): 154-161.

Muturi E.J., Kim C.H., Alto B.W., Berenbaum M.R., Schuler M.A. 2011. Larval environmental stress alters Aedes aegypti competence for Sindbis virus. Tropical Medicine and International Health 16(8): 955-964.

NagPal B.N., SRivastava A., Saxen R., Ansari M.A., Dash A.P., Das S.C. 2005. Pictorial identification key for Indian anophelines. Malaria Research Centre (ICMR), New Delhi, India

NAKSAThit A.T., EdMAn J.D., ScotT T.W. 1999. Partitioning of glycogen, lipid, and sugar in ovaries and body remnants of female Aedes aegypti (Diptera: Culicidae) fed human blood. Journal of Medical Entomology 36(1):18-22. 
NASCI R.S. 1986. The size of emerging and host-seeking Aedes aegypti and the relation of size to blood-feeding success in the field. Journal of American Mosquito Control Association 2(1): $61-62$.

Padmanabha H., BolKer B., LORD C.C., Rubio C., Lounibos L.P. 2011a. Food availability alters the effects of larval temperature on Aedes aegypti growth. Journal of Medical Entomology 48(5): 974-984.

Padmanabha H., Lord C.C., Lounibos L.P. 2011b. Temperature induces trade-offs between development and starvation resistance in Aedes aegypti (L.) larvae. Medical and Veterinary Entomology 25(4): 445-453.

PAULSON S.L., HAwley W.A. 1991. Effect of body size on the vector competence of field and laboratory population of Aedes triseriatus for La Crosse virus. Journal of American Mosquito Control Association 7(2): 170-175.

Richards S.L., ANDERSOn S.L., Alto B.W. 2012. Vector competence of Aedes aegypti and Aedes albopictus (Diptera: Culicidae) for dengue virus in the Florida Keys. Journal of Medical Entomology 49(4): 942-946.

Sharmila Bharathi N, Prasad NG, Shakarad M, Joshi A. 2004. Correlates of sexual dimorphism for dry weight and development time in five species of Drosophila. Journal of Zoology 264(1): $87-95$.

SHIN S.M., AKRAM W., LEE J.J. 2012. Effect of body size on energy reserves in Culex pipiens pallens females (Diptera: Culicidae). Entomological Research 42(3): 163-167.

STRICKMAn D., KitTAYAPONG P. 2003. Dengue and its vectors in Thailand: calculated transmission risk from total pupal counts of Aedes aegypti and association of wing-length measurements with aspects of the larval habitat. American Journal of Tropical Medicine and Hygiene 68(2): 209-217.

Sumanochitrapon W., Strickman D., Sithiprasasna R., Kittayapong P., InNis B.L. 1998. Effect of size and geographic origin of Aedes aegypti on oral infection with dengue-2 virus. American Journal of Tropical Medicine and Hygiene 58(3): 283-286.

TABACHNICK W.J. 2013. Nature, nurture and evolution of intra-species variation in mosquito arbovirus transmission competence. International Journal of Environmental Research and Public Health 10(1): 249-277.

TAKAhASHI M. 1976. The effects of environmental and physiological conditions on the pattern of transmission of Japanese encephalitis virus. Journal of Medical Entomology 13(3): 275-284.

TAKKEN W., KlOWden M.J., ChAmbers G.M. 1998. Effect of body size on host-seeking and blood meal utilization in Anopheles gambiae sensu stricto (Diptera: Culicidae); the disadvantage of being small. Journal of Medical Entomology 35(5): 639-645.

Telang A., Frame L., Brown M.R. 2007. Larval feeding duration affects ecdysteroid levels and nutritional reserves regulating pupal commitment in the yellow fever mosquito Aedes aegypti (Diptera: Culicidae). The Journal of Experimental Biology 210(5): 854-864.

Telang A., Li Y., Noriega F.G., Brown M.R. 2006. Effects of larval nutrition on the endocrinology of mosquito egg development. The Journal of Experimental Biology 209(4): 645-655.

Tsurim I., Silberbush A., Ovadia O., Blaustein L., Margalith Y. 2013. Inter- and intra-specific density-dependent effects on life history and development strategies of larval mosquitoes. PLoS ONE 8(3): e57875. 
Vaidyanathan R., Fleisher A.E., Minnick S.L., Simmons K.A., Scott T.W. 2008. Nutritional stress affects mosquito survival and vector competence for West Nile virus. Vector-Borne and Zoonotic Diseases 8(6): 727-732.

VAN HANDEL E. 1965. Microseparation of glycogen, sugars, and lipids. Analytical Biochemistry 11(2): 266-271.

VAN HANDEL E. 1985a. Rapid determination of glycogen and sugars in mosquitoes. Journal of the American Mosquito Control Association 1(3): 299-301.

VAN HANDEl E. 1985b. Rapid determination of total lipids in mosquito. Journal of the American Mosquito Control Association 1(3): 302-304.

WHO [World Health ORganisation] 2003. Malaria entomology and vector control. Learner's guide. World Health Organization, Geneva.

Yu B-T., Dinga Y-M., Mo X-C., Liub N., Li H-J., Mo J-C. 2016. Survivorship and fecundity of Culex pipiens pallens feeding on flowering plants and seed pods with differential preferences. Acta Tropica 155: 51-57.

ZAR J.H. 1999. Biostatistical analysis. Fourth Edition. Pearson Education Singapore Private Limited (Indian Branch), New Delhi, India.

Received: 25 August 2016

Accepted: 7 November 2016 